\title{
Editorial
}

\section{Need of Self-Management Education for Iraqi Diabetic Patients}

\author{
Ehab Mudher Mikhael ${ }^{1,2}$ Mohamed Azmi Hassali² \\ ${ }^{1}$ Department of Clinical Pharmacy, College of Pharmacy, University \\ of Baghdad, Baghdad, Iraq \\ 2Department of Social and Administrative Pharmacy, School of \\ Pharmaceutical Sciences, Universiti Sains Malaysia, Pulau Pinang, \\ Malaysia \\ ${ }^{3}$ Department of Pharmacology and Toxicology, Faculty of Pharmacy, \\ Al-Rafidain University College, Baghdad, Iraq
}

Saad Abdulrahman Hussain ${ }^{3}$

J Soc Health Diab:2020;8:1-2

Iraq is facing an epidemic of diabetes mellitus (DM), with a prevalence of approximately 20\%; such prevalence has significantly increased ( $\sim$ times) in the last four decades, and it is expected to continue rising in the future. ${ }^{1}$ Long-term DM complications are common (approaching 80\% for some microvascular complications [retinopathy and neuropathy]; 25-48\% for macrovascular complications [cardiovascular diseases and stroke respectively]) and significantly higher among Type 2 DM (T2DM) patients living in Iraq than those living in other regions of the world. ${ }^{2,3}$ The main cause for the high-prevalence of DM complications maybe attributed to the poor glycemic control among Iraqi T2DM patients at which $\geq 76 \%$ of the Iraqi DM patients couldn't reach their glycemic target. ${ }^{4}$ The main reason that prevents achievement of good glycemic control is the poor adherence to both antidiabetic medications and lifestyle modifications (diet and physical activity). ${ }^{5}$ This low-adherence to pharmacological and nonpharmacological treatment of DM is mainly attributed to the lack of awareness and knowledge about the seriousness of diabetes, importance of diabetes management, and how to manage DM appropriately. ${ }^{6}$ Reasons for poor diabetes knowledge among Iraqi DM patients are widely heterogeneous and conflicting in literature, including formal education, gender, duration of DM, type of medication and age; however, all studies agreed in that lacking of sufficient diabetic patient education is the main cause for such poor knowledge. ${ }^{7,8}$

This high-prevalence of DM and its complications in Iraq is associated with a devastating economic burden. ${ }^{9}$ On the other hand, opportunities for preventing and treating such complications are limited in Iraq. ${ }^{10}$ All these necessitate the need to improve glycemic control among Iraqi DM patients to prevent or, at least, postpone DM complications, rate of hospitalization, and hence, the burden on health institutions. The main way to improve glycemic control is through improving DM patients' knowledge and awareness about DM and its management by educating DM patients about appropriate diabetes self-management behaviors and practices. Unfortunately, till now, no comprehensive diabetes self-management educational program is adopted in Iraq. ${ }^{11}$ Although many diabetes self-management educational programs are developed and tested with positive outcomes in different countries but not one can be directly adopted, because they are evaluated in countries where patients have different health beliefs, practices, social and ethnic structures from Iraqi patients. ${ }^{12}$ Hence, the development and evaluation of an Iraqi-specific DSME program is crucial.

\section{Conflict of Interest}

None declared.

\section{References}

1 Mansour AA, AL Douri F. Diabetes in Iraq: facing the epidemic. A systematic review. Wulfenia 2015;22(3):258-278

2 Litwak L, Goh SY, Hussein Z, Malek R, Prusty V, Khamseh ME. Prevalence of diabetes complications in people with type 2 diabetes mellitus and its association with baseline characteristics in the multinational A1chieve study. Diabetol Metab Syndr 2013;5(1):57

3 Almayahi BA. Diabetes mellitus and its complications in Najaf City, Iraq. Am J Biol Life Sci 2015;3(5):181-186

4 Yaseen OY, Atyia JJ. Facts about type 2 diabetes mellitus and its control in Misan governorate: single center experience. Med J Basrah Univ 2018;36(2):81-86

5 Raheem YA. Compliance issue in Type II Diabetes: does it reduce the prevalence of cardiovascular risk factors? Iraqi Postgrad Med J 2010;9(2):125-134

6 Aladhab RA, Alabbood M. Adherence of patients with diabetes to a lifestyle advice and management plan in Basra, Southern Iraq. Int J Diabetes Metab 2019. Doi: 10.1159/000500915

\section{Address for correspondence}

Ehab Mudher Mikhael, MD, Social,

Pharmacy/Clinical Pharmacy Universiti Sains

Malaysia/University of Baghdad, Iraq

(e-mail: ehab_pharma84@yahoo.com).
DOI https://doi.org/ $10.1055 / \mathrm{s}-0040-1715994$ ISSN 2321-0656. (c) 2020. Novo Nordisk Education Foundation.

This is an open access article published by Thieme under the terms of the Creative Commons Attribution-NonDerivative-NonCommercial-License, permitting copying and reproduction so long as the original work is given appropriate credit. Contents may not be used for commercial purposes, or adapted, remixed, transformed or built upon. (https://creativecommons. org/licenses/by-nc-nd/4.0/).

Thieme Medical and Scientific Publishers Pvt. Ltd. A-12, 2nd

Floor, Sector 2, Noida-201301 UP, India 
7 Khurshid T, Othman S. Knowledge and practice about diabetes among adult diabetic patients in Erbil, Iraq. Zanco J Med Sci 2018;18(1):659-666

8 Abbas SQK, Al-Tukmagi HF, Al-Auqbi TF. Assessment of knowledge, attitude and practice in a sample of Iraqi type 2 diabetic patients. Al-Qadisiya Med J 2015;11(21):100-106

9 DaRocha FernandesJD, HuangY, KarurangaS, et al. Health expenditure on diabetes in the Middle East and North Africa region in 2017

10 Zhang P, Zhang X, Brown J, et al. Global healthcare expenditure on diabetes for 2010 and 2030. Diabetes Res Clin Pract 2010; 87:293-301.
11 Zabetian A, Kelli HM, Echouffo-Tcheugui JB, Narayan KM, Ali MK. Diabetes in the Middle East and North Africa. Diabetes Res Clin Pract 2013;101(2):106-122

12 Beck J, Greenwood DA, Blanton L, et al; 2017 Standards Revision Task Force. 2017 Standards Revision Task Force. 2017 national standards for diabetes self-management education and support. Diabetes Educ 2017;43(5):449-464 